See discussions, stats, and author profiles for this publication at: https://www.researchgate.net/publication/279635712

\title{
The Black Sea basin filling by the Mediterranean salt water during the Holocene
}

Article in Quaternary International · June 2016

DOI: 10.1016/.j.quaint.2015.05.011

CITATIONS

2

4 authors, including:

Nikolay Esin

P.P. Shirshov Institute of Oceanology

37 PUBLICATIONS 81 CITATIONS

SEE PROFILE

Valentina Yanko

Odessa National University

81 PUBLICATIONS 1,223 CITATIONS

SEE PROFILE

Some of the authors of this publication are also working on these related projects:

Project Meiobenthos of methane outlets of the Black Sea View project

Project Evolutionary mechanisms of the Black Sea and Caspian Sea View project
Nikolay Igorevich Esin

P.P. Shirshov Institute of Oceanology

15 PUBLICATIONS 28 CITATIONS

SEE PROFILE 


\title{
The Black Sea basin filling by the Mediterranean salt water during the Holocene
}

\author{
N.V. Esin ${ }^{\mathrm{a},{ }^{*}, \text { N.I. Esin }}{ }^{\mathrm{a}}$, V. Yanko-Hombach ${ }^{\mathrm{b}, \mathrm{c}}$ \\ a Southern Branch of the P.P. Shirshov Institute of Oceanology, Russian Academy of Science, Gelendzhik, Krasnodar Region, 353467, Russian Federation \\ ${ }^{\mathrm{b}}$ Odessa I.I.Mechnikov National University, 2 Dvoryanskaya Str., Odessa 65082, Ukraine \\ ${ }^{\mathrm{c}}$ Avalon Institute of Applied Science, 976 Elgin Ave., Winnipeg, MB, Canada, R3E 1B4
}

\section{A R T I C L E I N F O}

\section{Article history:}

Available online 30 June 2015

\section{Keywords:}

Black Sea filling by the salt water

Holocene

Bosphorus Strait

Mathematical model of two layer flow

\begin{abstract}
A B S T R A C T
The origin of the bottom counterflow in Bosphorus Strait during the early Holocene, its temporal development and the Black Sea filling by the Mediterranean salt water is discussed in this paper. At $10 \mathrm{ka}$, the depth of the strait was $10 \mathrm{~m}$, the velocity of accumulation body growth in the southern part of the strait was $3 \mathrm{~mm} / \mathrm{year}$, and the velocity of the ocean transgression was $13.5 \mathrm{~mm} / \mathrm{year}$. The freshwater balance of the Black Sea is accepted as it is now. Based on mathematical modeling the bottom counterflow breakthrough occurred when the depth of the strait was $16.5 \mathrm{~m}$, at about 9400 years ago. Before this, salt water penetrated into the Black Sea in the autumn-winter seasons during short periods of time, when the Bosphorus upper stream was absent. The Navier-Stokes equations were used to describe the water circulation. Temporal dependencies of the counterflow depth, water discharge in counterflow and depth of the halocline in the Black Sea was calculated.

The halocline reached the depth of $100 \mathrm{~m}$ about 7200 years ago, and a situation close to present one (the lower Bosphorus flow brought salt into the Black Sea, with the upper stream returning it to the Sea of Marmara. The water discharge in the low water layer was insignificant during the time interval from 9400 to 8400 years ago. Then, it quickly rose to about $700 \mathrm{~km}^{3} /$ year.
\end{abstract}

(C) 2015 Elsevier Ltd and INQUA. All rights reserved.

\section{Introduction}

In several papers concerning the study of the Black Sea level changes (Esin et al., 2010, 2011, 2013; Esin and Esin, 2012, 2014) a method of physical (mathematical) description of the geological processes is applied. This method allows connecting geological events which happened at different times in a continuous time series, in which each subsequent event is prepared by previous geological history.

In the present paper we attempt to describe the process of the Black Sea basin filling by salt Mediterranean Sea water in condition of a sufficiently deep strait. The question about the minimum depth of the strait, when arose counterflow there, has been debated repeatedly in the literature (Lane-Serff et al., 1997). This depth depends on the freshwater balance of the Black Sea. The larger is the freshwater balance value, the greater is the strait depth, when the salt water can penetrate into the Black Sea.

\footnotetext{
* Corresponding author.

E-mail addresses: ovos_oos@mail.ru (N.V. Esin), esinnik@rambler.ru (N.I. Esin), valyan@onu.edu.ua (V. Yanko-Hombach).
}

Water circulation of two-layer flow in the Bosphorus Strait is described by the equation system of Navier-Stokes. In earlier papers, the Boussinesq, Bernoulli, and Saint-Venant equations were used. They are Euler equations for ideal liquid, averaged in vertical direction. There is no friction mechanism between layers of viscous fluid. In the case of two-layer flow friction determines the position of interface between upper and near-bottom currents. Shearing stresses on the interface have equal values from above and below, but opposite direction. Such a mechanism forms the process of capturing a certain value of water from the low stream by the upper stream and its returning to the Marmara Sea. Gregg and Ozsoy (2002) used a full hydrodynamical model in the form of Navier-Stokes equations, diffusion equations, and equation of fluid state. However, it is not expedient to use such a model for the description of geological processes as there are insufficient data about hydrodynamic conditions in the Holocene.

\section{Mathematical model of two-layer flow}

According to theoretical conclusions of previous investigations (Esin et al., 2010, Esin and Esin, 2014) based on geological and other studies (Ostrovsky et al., 1977; Serebrinanii, 1982; Lane-Serff et al., 
1997; Izmailov, 2005), about 10000 years ago the levels of the Black and Marmara seas converged and a Bosphorus Strait with depth of about $10 \mathrm{~m}$ formed. Thereafter, the oceanic transgression of the Black Sea began. The Black Sea level repeated the Marmara Sea level course with an excess of a few tens of centimeters. The depth of the strait was being increased and counterflow arose. Temporal discharge in counterflow increased over time. We describe, with the use of Navier-Stokes equations, two-layer water flow in the strait with depth increasing. The flow diagram is presented in Fig. 1.

In the upper layer of Bosphorus Strait, the Black Sea water flows to the Marmara Sea, as the result of the Black sea level being higher than the Marmara sea level. Water flows due to pressure gradient, which is created by the free water surface inclination in the strait. In this case the bottom of the upper stream is the interface between flow and counterflow. On the bottom water motion velocity is equal to zero and on the free surface shearing stress is equal to zero.

Within the bottom water flows under the influence of two factors - pressure gradient, created by the inclination of the free water surface and due to the fact that the Marmara Sea water is denser than that of the surrounding Black Sea water by $\sim 0.03 \mathrm{~g} / \mathrm{cm}^{3}$. Therefore heavy water flows along the bottom.

For the description of the upper stream $X_{u p}$ axis must be directed towards the Marmara Sea and $Z_{u p}$ axis is directed upwards (Fig. 1). In the case of quasi-stationary sum, when the process of a slow change of a mean value of the Black Sea freshwater balance (during several millenniums), members of Navier-Stokes equations describing viscosity are of $10^{-3}-10^{-4} \mathrm{~m} / \mathrm{s}^{2}$ order and members describing acceleration $-10^{-10} \mathrm{~m} / \mathrm{sec}^{2}$. We may neglect inertia and describe the upper stream in the Bosphorus Strait by Navier-Stokes equations as:

$$
-\frac{1}{\rho} \frac{\partial P_{u p}}{\partial x_{u p}}+\nu \frac{\partial^{2} U_{u p}}{\partial z_{u p}^{2}}=0 ;
$$

$\frac{\partial P_{u p}}{\partial z_{u p}}=-\rho g$

$$
\int_{o}^{H_{u p}} U_{u p} d z_{u p}=Q_{u p} / l .
$$

where $\rho$ - water density within the upper stream, $P_{u p}-$ pressure, $\nu$ - kinematic viscosity coefficient, $Q_{u p}$ - water discharge, 1 - width of the Strait.

Solution of (1)-(3) equations can be written as:

$P_{u p}=\rho g\left(H_{u p}-z_{u p}\right)$

$U_{u p}=\frac{g}{2 \nu} \frac{d H_{u p}}{d x_{u p}} z_{u p}\left(2 H_{u p}-z_{u p}\right)$

$H_{u p}^{4}=H_{0}^{4}+\frac{12 \nu Q_{u p}}{g l}\left(L-x_{u p}\right)$

or:

$H_{u p}^{4}=\left(H_{u p}-\Delta H\right)^{4}+\frac{12 \nu Q_{u p}\left(L-x_{u p}\right)}{g l}$.

Here $H_{u p}$ - water surface in the strait, $H_{0}$ - depth of the upper stream near the entrance to the Marmara Sea, $\Delta H$ - difference between the levels of neighboring seas, $L$ - length of the strait from the southern sill to the Black Sea $(L=20000 \mathrm{~m})$.

In the low layer, water is denser (roughly $0.03 \mathrm{~g} / \mathrm{cm}^{3}$ ) than the Black Sea water. This water flows downstream along the bottom under the influence of gravity. Another factor influencing the nearbottom water is a pressure gradient, originated by the inclination of the upper stream water surface to the sea-line. This gradient is directed against the current within the nearbottom layer. When water surface in the strait is approximated as a straight line, then a pressure gradient does not depend on $X$ and is equal to $\rho g \cdot \operatorname{tg} \varphi$, where $\operatorname{tg} \varphi$ - the average slope of water surface which is of the order from $10^{-6}$ to $10^{-5}$. Now, Navier-Stokes equations can be written as:

$g \frac{\Delta \rho}{\rho_{s}} \sin \alpha-g \operatorname{tg} \varphi+\nu \frac{\partial^{2} U_{d n}}{\partial z_{d n}^{2}}=0 ;$

$g \frac{\Delta \rho}{\rho_{S}} \cos \alpha-\frac{1}{\rho_{S}} \frac{d P}{d z_{d n}}=0$

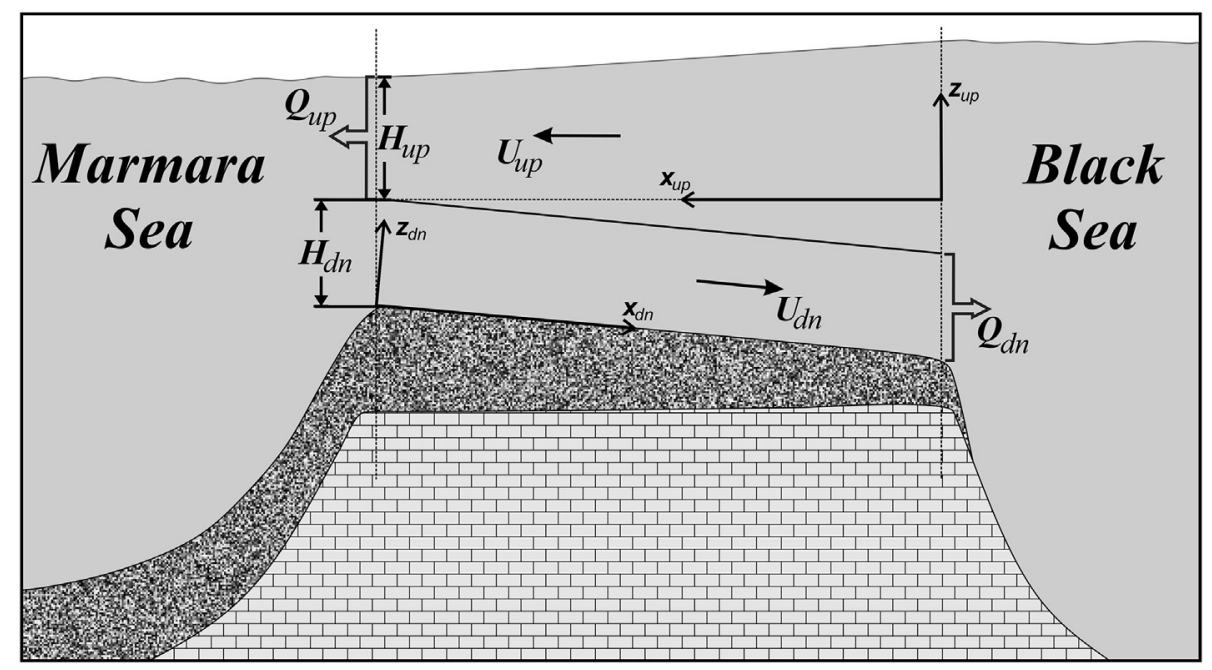

Fig. 1. The scheme of the water circulation in the Bosporus Strait. 
$\int_{0}^{H_{d n}} U_{d n} d z_{d n}=\frac{Q_{d n}}{l}$

Here $\alpha$ - angle of the bottom slope in the point of minimum depth $\left(\alpha \approx 1,2 \cdot 10^{-3}\right), \Delta \rho=\rho_{s}-\rho$, where $\rho_{s}$ - density of the Marmara Sea water, $\rho$ - density of the Black Sea water, $U_{d n}$ - current velocity, $Z_{d n}$ axis is directed upwards.

Taking into consideration that the density gradient is directed against the bottom counterflow, the solution of the equation system can be written as:

$P=\Delta \rho g\left(H_{d n}-z_{d n}\right) \cos \alpha$

$U_{d n}=\frac{g}{2 \nu}\left(\frac{\Delta \rho}{\rho_{s}} \sin \alpha-\operatorname{tg} \varphi\right)\left(H_{d n} z_{d n}-z_{d n}^{2}\right)$

$Q_{d n}=\frac{g l H_{d n}^{3}}{12 \nu}\left(\frac{\Delta \rho}{\rho_{s}} \sin \alpha-\operatorname{tg} \varphi\right)$

The depth of the lower flow does not depend on the depth of the strait. The second condition is that the shear stresses are equal in magnitude and opposite in direction at the boundary line of the upper flow and lower counter-flow. In this condition, the depth of the strait is one of the main factors.

Present-day research in the strait (Jarosz et al., 2011) showed that the coefficient $\nu$ varies from $10^{-3}$ to $10^{-2} \mathrm{~m}^{2} / \mathrm{s}$ and larger values, depending on the wind and the flow velocity. The water discharge $Q_{u p}$ and $Q_{d n}$ also vary from zero to a maximum value during the year. Therefore, within quasi-stationary sum, the parameters $\nu$ and $\sin \alpha$ are chosen in such a way that in the strait the average annual water discharge in the upper and lower flows conform to their present values. Thus we have $\nu=1.6 \cdot 10^{-2} \mathrm{~m}^{2} / \mathrm{s}$ and $\sin \alpha=1.2 \cdot 10^{-3}$. From (13) it is obtained $Q_{u p}=570 \mathrm{~km}^{3} /$ year $\left(18075 \mathrm{~m}^{3} / \mathrm{s}\right) . H_{d n} \approx 12 \mathrm{~m}$, that is close to the calculated values obtained by Oguz et al. (1990) for the water discharge in the upper flow.

In the article of Oguz et al. (1990), as well as Ozsoy et al. (1998), the main features of water circulation in the strait are described. The authors showed that the depth of counterflow depends on the water discharge in the upper flow: the more $Q_{u p}$ the shallower counterflow. Counterflow disappears when the value of $Q_{u p}$ is sufficiently large. With increasing $Q_{u p}$ from $4380 \mathrm{~m}^{3} / \mathrm{s}$ to $21765 \mathrm{~m}^{3} /$ $s$ the depth of the counterflow decreases roughly from 14 to $8 \mathrm{~m}$. If there is no upper stream, the flow develops in the direction of the Black Sea. A mechanism of a single-layer flow had been set also on the field observation data (Jarosz et al., 2011). One more feature of the water circulation in the strait is a self-regulating mechanism which supports a certain water discharge in the upper stream, depending on the depth of the strait. According to Oguz et al. (1990), lower flow disappears when $Q_{u p} \geq 26000 \mathrm{~m}^{3} / \mathrm{s}$ (based on calculations) and $Q_{u p} \geq 46000 \mathrm{~m}^{3} / \mathrm{s}$ based on the results of field measurements. In conditions of quasi-stationary sum, we assume that the water discharge in the upper flow is equal to the water discharge in the lower flow plus the freshwater balance of the Black Sea: $Q_{u p}=Q_{d n}+Q_{f r e s h}$ Taking into account the previously obtained formulas, we have:

$Q_{\text {fresh }}=\frac{\left[H_{u p}^{4}-\left(H_{u p}-\Delta H\right)^{4}\right] g l}{12 \nu L}-\frac{g l H_{d n}^{3}}{12 \nu}\left(\frac{\Delta \rho}{\rho_{s}} \sin \alpha-\operatorname{tg} \varphi\right)$.

Equation (14) makes it possible to calculate the depth of the strait where the counterflow could be formed, if the freshwater balance of the Black Sea was about the same as it is now, i.e. it was about $240 \mathrm{~km}^{3} /$ year $\left(7610 \mathrm{~m}^{3} / \mathrm{s}\right)$, and the average level difference of the neighboring seas was $0.3 \mathrm{~m}$.

If $H_{d n}=0$ in (14), we obtain an algebraic equation:

$Q_{f r e s h}=\frac{\left[H_{u p}^{4}-\left(H_{u p}-0,3\right)^{4}\right] g l}{12 \nu L}$.

It follows from this that the salt water debacle occurred when the strait depth was $16.5 \mathrm{~m}$. According to Lane-Serff et al. (1997), the debacle of the Mediterranean salt water to the Black Sea occurred at the strait depth being $11 \mathrm{~m}$, when the freshwater balance of the Black Sea was equal to $10000 \mathrm{~m}^{3} / \mathrm{s}$, and the strait width was $500 \mathrm{~m}$.

Equation (15) shows that the minimum depth in the strait, when counterflow can arise, depends on $v$ which varies depending on hydrometeorological situation.

When the upper flow is absent, the salt Marmara water broke through the strait and then into the Black Sea at any depth of the strait. According to the present data, the freshwater balance of the Black Sea for a short time (1-2 months) becomes negative in autumn and winter months (Zhiljaev and Esin, 1990). At this time, salt Mediterranean water flows into the Black Sea throughout the depth of the strait. Such a short salt water influx probably may take place a few hundred years earlier than 9500 years ago, i.e. the time when it was recorded by geological methods.

\section{Model of the Bosphorus Strait depth changing during the Holocene}

The question of the Bosporus Strait formation is debatable. In this paper we discuss an idea of the strait evolution based on the physical knowledge of the processes taking place in it. In accordance with the mathematical model presented in the article (Esin and Esin, 2014) and adapted by the geological curve of Izmailov (2005), the levels of the Black and Marmara seas became much closer at about 10000 years ago, and the oceanic transgression of two seas began with velocity of about $13.5 \mathrm{~mm} / \mathrm{y}$ (Rohde, 2007). At the same time the sedimentation and accumulated body formation were occurred in the southern part of the strait. Assume that the velocity of the accumulation body raise was $3 \mathrm{~mm} / \mathrm{year}$ for the last 10 thousand years, and the relative velocity of the level uplifting was $13.5-3=10.5 \mathrm{~mm} /$ year or $10.5 \mathrm{~m}$ per 1000 years. The depth of the strait was $10 \mathrm{~m}$ at the beginning of the oceanic transgression. During the next 600 years, i.e. about 9400 years ago, the depth of the strait increased to $16.5 \mathrm{~m}$, and the counterflow was formed. Previously, salt water entered the Black Sea when the outflow from the Black Sea disappeared during the short autumn and winter periods (Zhiljaev and Esin, 1990). Let's calculate the volume of salt water flowing into the Black Sea since 9400 years ago, taking into account that the level of the Black Sea could not be above the level of the Marmara Sea more than $0.4 \mathrm{~m}$. During the first 500 years after the counterflow formation the process was being developed in a regime when its depth was less than the critical depth at which the upper flow blocked the increasing of the lower flow depth. But after about 500 years the water circulation happened in conditions of self-regulation of the lower flow when the difference of sea levels was $0.4 \mathrm{~m}$.

We assume that the velocity of the strait depth increase was $10.5 \mathrm{~mm} /$ year. If the depth of the strait was $10 \mathrm{~m}$ near the entrance to the Marmara Sea 10000 years ago, then the increase was: $H^{\prime}=H_{u p}+H_{d n}=10 \mathrm{~m}+10 \cdot(5 \mathrm{~mm} / \mathrm{yr}) \cdot t$, where $H^{\prime}-$ is the depth of the strait at the entrance to the Marmara Sea.

We can also assume that the process of the Black Sea basin filling by salt water occurred with the difference of neighboring seas depths being $0.4 \mathrm{~m}$. We can obtain an algebraic equation for $H_{d n}(t)$. 


$$
\begin{aligned}
& \frac{g l H_{d n}^{3}}{12 \nu}\left(\frac{\Delta \rho}{\rho_{s}} \sin \alpha-\operatorname{tg} \varphi\right)+Q_{\text {fresh }}=\frac{g l}{12 \nu} \\
& \cdot\left[\left(16,5+0,0105 t-H_{d n}\right)^{4}-\left(16,1+0,0105 t-H_{d n}\right)^{4}\right] .
\end{aligned}
$$

The calculated curve $H_{d n}(t)$ is presented in Fig. 2. Calculations showed that the increasing of the counterflow depth was considerably slower than a total deepening of the strait as a result of the ocean-level rise. The velocity of the strait depth increasing was $10.5 \mathrm{~mm} /$ year, and the velocity of the lower flow depth increasing was only $4.7 \mathrm{~mm} /$ year. Thus, the increment of the total strait depth is distributed between the upper and lower flows. Calculations were performed for two possible variants: $\Delta H=0.4 \mathrm{~m}$ and $\Delta H=0.3 \mathrm{~m}$. Fig. 2 also shows that, when $\Delta \mathrm{H}=0.3 \mathrm{~m}$ counterflow appeared earlier than if $\Delta H=0.3 \mathrm{~m}$. When the value is even less, a counterflow appears earlier. Thus, before the regular counterflow appearing, when $\Delta H=0.3 \mathrm{~m}$, currents of salt water of short duration were formed in the nearbottom layer. Salinization of the Black Sea water began not 9500 years ago but greatly before. This cannot be revealed by geological methods since water discharge was small.

Curve $H_{d n}(t)$ allows calculation of the volume of salt water, accumulating in the Black Sea:

$\sum Q_{d n}=\frac{g \Delta \rho l \sin \alpha}{12 \rho_{s} \nu} \sum_{t=0}^{t=3000} H_{d n}^{3} \Delta t$.

Curves summarizing the volume of salt water that came into the Black Sea, as a result of counterflow development, are shown in Fig. 3. The figure shows that a very small amount of salt water entered in the sea for the first 500 years. It is very likely that this water was dispersed in the sea by currents. In this case, the average concentration of the salt in the sea could increase very slightly. 1000 years later, the process of the Black Sea salinization quickly escalates. Fig. 2 shows also that the lower $\Delta H$ and correspondingly flow intensity in the upper water layer the earlier counterflow arise (in condition of the sea level transgression). Performed calculation has shown that filling of the Black Sea by bottom counterflow occurred very quickly. An evident filling began about 8400 years ago. The difference between the curves $a$ and $b$ is not more than 200 years.

In the Black Sea basin, there is $537 \cdot 10^{3} \mathrm{~km}^{3}$ of water. The upper $100 \mathrm{~m}$ thick layer contains $36.7 \cdot 10^{3} \approx 37 \cdot 10^{3} \mathrm{~km}^{3}$. Consequently, $5 \cdot 10^{5} \mathrm{~km}^{3}$ of water are present from the bottom up to the depth of $100 \mathrm{~m}$. When the boundary of salt water (or more precisely, the halocline surface) rose to the present depth of $100 \mathrm{~m}$, a situation close to the present-day took place. It is characterized by lifting of water with salinity of $16-18^{00} \%$ to the sea surface and flow into the Marmara Sea. Thus, $5 \cdot 10^{5} \mathrm{~km}^{3}$ of the Mediterranean water accumulated in the Black Sea by the time of 7200-7000 years ago, and salt removal from the sea started by the upper flow.

Roughly 7000 years ago, the velocity of the ocean level rising sharply dropped to an average value of $0.5 \mathrm{~mm} /$ year (Rohde, 2007). The strait became shallower due to accumulation and its depth had been reduced to $36 \mathrm{~m}$ by the present time.

When the depth of counterflow $H_{d n}=16 \mathrm{~m}$ (the maximum value of $H_{d n}$ was $7200-7000$ years ago), $22405 \mathrm{~m}^{3} / \mathrm{s}$ (or $707 \mathrm{~km}^{3} /$ year) of salt water have been flowed into the Black Sea, i.e. approximately 2 times more than at present. The average depth of counterflow decreased to $12 \mathrm{~m}$. As a result, water discharge decreased. This has happened owing to the lessening the difference between salt and fresh water density.

A curve of the depth temporal changes of hydrogen sulfide pollution in the Black Sea obtained by geological methods is known (Sorokin, 2002) Fig. 5. Hydrogen sulfide pollution took place after the salinization of water, and it depends on the consumption of oxygen by hydrobionts and on the oxidation of hydrogen sulfide. Theoretically, the curve of temporal change of hydrogen sulfide pollution and salt water surface must be close to each other. However, the curves shown in Figs. 4 and 5 are substantively different. The hydrogen sulfide pollution curve does not take into account the fact that the Black Sea filling by salt water happened with increasing velocity, initiated by the increasing of counterflow depth.

The content of our work is close to Lane-Serff et al. (1997), in which the process of the Black Sea basin filling by salt Mediterranean water is discussed. However, investigation methods are substantively different. Lane-Serff et al. did calculations for two fixed

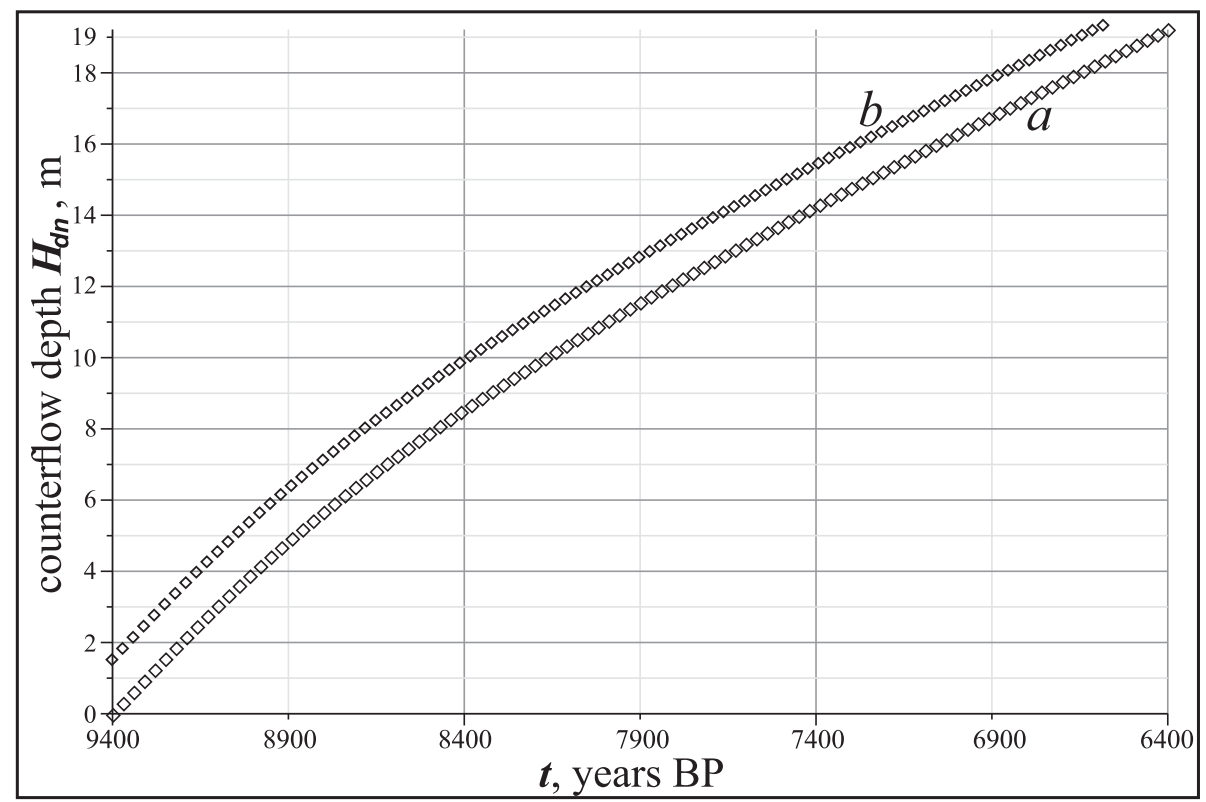

Fig. 2. The depth of the counterflow $H_{d n}$ changing in time. The calculations were performed with $a-$ being $\Delta H=0.4 \mathrm{~m}, b-$ with $\Delta H=0.3 \mathrm{~m}$. 


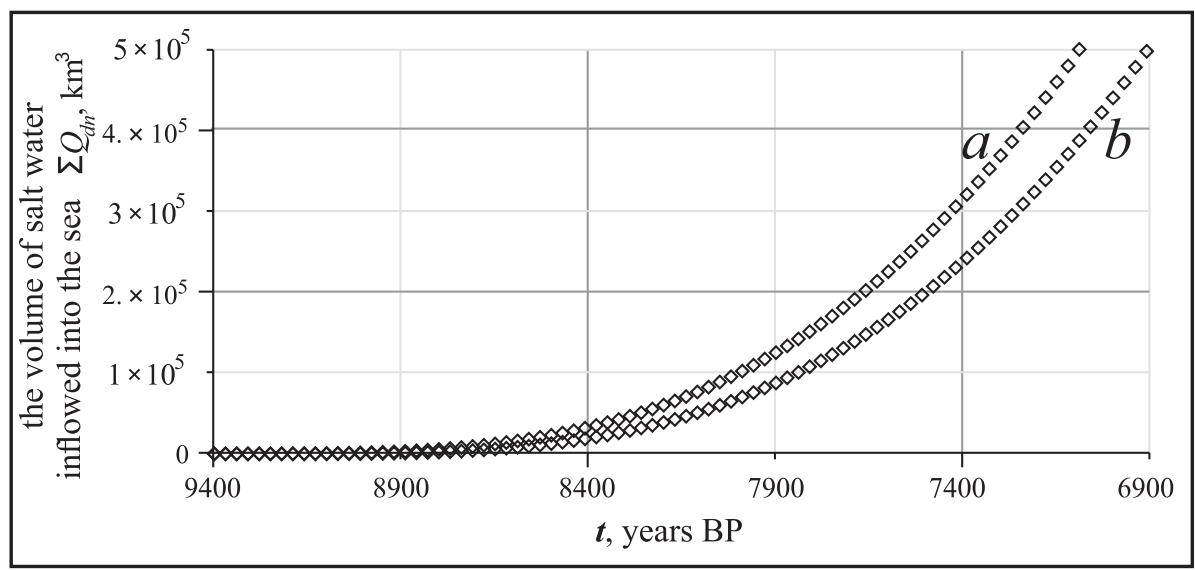

Fig. 3. The volume of salt water inflowed into the Black Sea for the time $t$. The calculation is done: $a-$ when $\Delta H=0.4 \mathrm{~m}, b-$ when $\Delta H=0.3 \mathrm{~m}$.

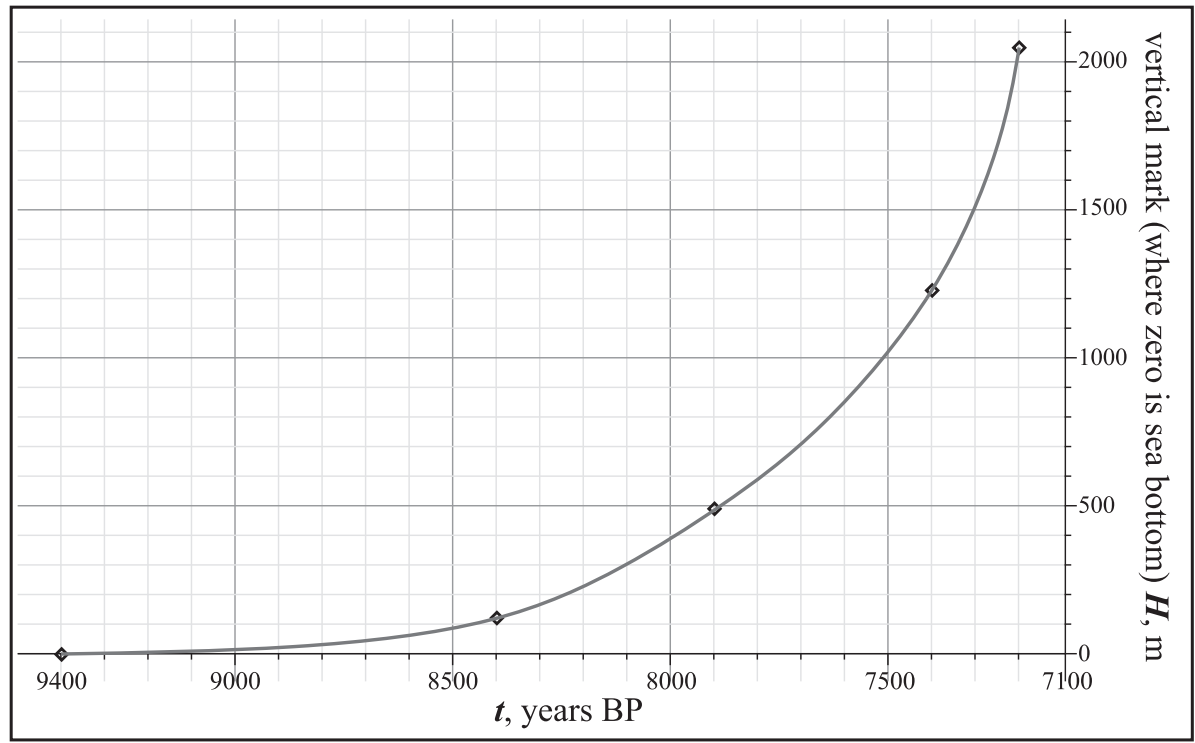

Fig. 4. The graph of the Black Sea basin filling by the Mediterranean salt water. Curve $H(t)$ indicates the rise of the halocline level.

situations of current in the nearbottom layer: the strait depth is $40 \mathrm{~m}$ (water discharge is $10000 \mathrm{~m}^{3} / \mathrm{s}$ ) and $60 \mathrm{~m}$ (water discharge is $20000 \mathrm{~m}^{3} / \mathrm{s}$ ). Under real conditions, thickness of water layer of bottom counterflow grows from zero to a certain fixed value. In our

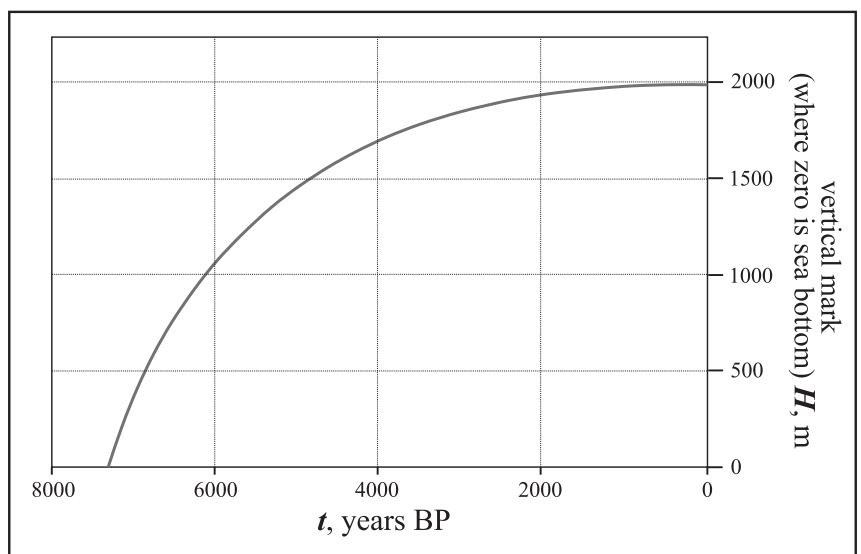

Fig. 5. Process of hydrogen sulfide pollution in the Black Sea during the last 7300 years, according to geological studies (Sorokin, 2002). calculation it is about $18 \mathrm{~m}$, Lane-Serff et al. calculated $20 \mathrm{~m}$. About 7000 years ago the rate of the ocean level rise decreased to $0.5 \mathrm{~mm} /$ y. From this moment the strait depth decreased due to bottom accumulation. Our calculation using differential equations takes into consideration the growth of the strait depth, and later of the strait shallowing.

According to our calculation, the volume of fresh water in the Black Sea was exhausted about 7000 years ago. After this the bottom counterflow began to carry out from the Black Sea surface water to the Marmara Sea. Under such salinity, the water exchange between surface and bottom layers was restored in the Marmara Sea and the process of sapropel formation on the bottom stopped. According to Lane-Serff et al., this occurred 6400 years ago, close to our calculated value (7000 years ago).

Lane-Serff et al. assume that another mechanism of sapropel formation exists in the periods of low sea level. However, we think that there is only one mechanism of stagnant water accumulation on the bottom, namely filling with fresh water.

Earlier, we showed that during glacial epoch the Black Sea was a flowing lake with water discharge being 100-130 km³ $/ \mathrm{yr}$ (Esin et al., 2010, Esin and Esin, 2014). When the ocean level was low fresh water also flowed out from the Black Sea and spread over the surface of the Marmara Sea under definite hydrometeorological 
conditions (for example, during the period of damp climate). It was a barrier for vertical movements of water.

\section{Conclusion}

The mathematical model of two-layer water flow in the Bosporus Strait proposed in article and described by the Navier-Stokes equations reveals the main features of the process of NewEuxinian freshwater lake-sea extrusion by the salty and denser Mediterranean water. Calculations showed that the water inrush of the Mediterranean salt water to the Black Sea occurred about 9400 years ago, when the total Bosphorus depth was $16.5 \mathrm{~m}$ and the freshwater balance of the Black Sea was about the same as it is now. In the course of deepening of the strait the counterflow depth increased to $16 \mathrm{~m}$, and the water discharge to $707 \mathrm{~km}^{3} /$ year. The largest volume of salt penetrated into the Black Sea from 8000 to 7000 years ago. Then, the water discharge in the downstream decreased to the present values. An insignificant volume of the Mediterranean water entered into the Black Sea for the first thousand years. Then, the process of the Black Sea basin filling increased sharply. During the next 1400 years salt water rose to the presentday depth, $100 \mathrm{~m}$, and the process of salt removing from Black Sea in the upper flow began, about 7200 years ago. Slow salting of the Black Sea water began earlier than 9500 years ago.

The curve showing the upward movement of salt and fresh waters interface in the Black Sea has been calculated. The diffusion at the interface was not taken into account. Curves of the halocline and hydrogen sulfide pollution rise significantly differ. The twolayer flow model of the Black Sea basin filling by the Mediterranean salt water on the whole confirms the results of geological investigations.

\section{Acknowledgments}

The present work was fulfilled within the IGCP 610 project and RFFI grant 13-05-96525 Ruyug.

\section{References}

Esin, N.V., Esin, N.I., 2012. Ob izmenenii urovnja Mirovogo Okeana v golocene [Change in the level of the world ocean in the Holocene]. Doklady Akademii Nauk 447 (5), 568-570 (in Russian).
Esin, N.V., Esin, N.I., 2014. Mathematical modeling of the Black Sea level change for the last 20000 years. Quaternary International 345, 32-47.

Esin, N.V., Potutenko, E.N., Esin, N.I., 2011. Estimation of the Double-amplitude Peak of the Black Sea Level Secondary Fluctuations in Late Pleistocene-Holocene. In: Mathematical Modelling, vol. 6. Nova Science Publishers, pp. 243-254.

Esin, N.V., Zatsepin, A.G., Esin, N.I., 2013. The Black Sea and World Ocean Levels Change during the Holocene. Nova Science Publishers, USA, pp. 89-100. Holocene: Perspectives, Environmental Dynamics and Impact Events Chapter 8.

Esin, N.V., Yanko-Hombach, V.V., Kukleva, O.N., 2010. Mathematical model of the Late Pleistocene and Holocene transgressions of the Black Sea. Quaternary International 225, 180-190.

Gregg, M.C., Ozsoy, E., 2002. Flow, water mass changes, and hydraulics in the Bosphorus. Journal of Geophysical Research: Oceans 107 (C3). http://dx.doi.org/ 10.1029/2000JC000485.

Izmailov, Y.A., 2005. Jevoljucionnaja geografija poberezhij Azovskogo i Chjornogo morej [Evolutional geography of the Black Sea and Azov Sea]. Anapskaja peresyp' [Anapa barrier]. Sochi 1, 174 (in Russian).

Jarosz, E., Teague, W.J., Book, J.W., Besiktepe, S., 2011. On flow variability in the Bosphorus Strait. Journal of Geophysical Research 116 (C8). http://dx.doi.org/ 10.1029/2010JC006861.

Lane-Serff, G.F., Rohling, E.J., Bryden, H.L., Charnock, H., 1997. Postglacial connection of the Black Sea to the Mediterranean and its relation to the timing of sapropel formation. Paleoceanography 12, 169-174.

Oguz, T., Ozsoy, E., Latif, M.A., Sur, H.I., Unluata, U., 1990. Modeling of hydraulically controlled exchange flow in the Bosphorus Strait. Journal of Physical Oceanography 20, 945-965.

Ostrovskii, A.B., Izmailov, Y.A., Balabanov, I.P., 1977. Novye dannye o paleogidrologicheskom rezhime Chjornogo morja v verhnem plejstocene i golocene [New data on the paleohydrological regime of the Black Sea during the Upper Pleistocene and Holocene]. In: Paleogeografija I otlozhenija plejstocena uzhnyh morei SSSR [Paleogeography and Pleistocene Sediments of the Southern USSR Seas]. Moscow: Nauka, pp. 131-140 (in Russian).

Ozsoy, E., Latif, M., Besiktepe, S., Cetin, N., Gregg, M., Belokopytov, V., Goryachkin, Y., Diaconu, V., 1998. The Bosphorus Strait: exchange fluxes, currents and sea-leve changes. In: Ivanov, L., Oguz, T. (Eds.), Ecosystem Modeling as a Management Tool for the Black Sea, NATO Science Series 2, pp. 1-27.

Rohde, R.A., 2007. Image: Post-Glacial Sea Level. http://www.globalwarmingart $\mathrm{com} /$.

Serebrianii, A.B., 1982. Kolebanija urovnja Chjornogo morja v poslelednikovoe vremja i ih sopostavlenie s istoriej oledenenija vysokogornogo Kavkaza [Fluctuations of the Black Sea level during the postglacial period, and comparison with the history of the Caucasus mountain glaciatio'n]. In: Kolebanija urovnej morej i okeanov za 15000 let [Sea Level Change for the Last 15000 Years]. Moscow: Nauka, pp. 161-167 (in Russian).

Sorokin, Y.I., 2002. The Black Sea Ecology and Oceanography. Backhuys, Leiden, p. 875.

Zhiljaev, A., Esin, N.V., 1990. Vnutrigodovye fluktuacii rashoda vody cherez prolivy Bosfor i Kerchenskij [Subannual fluctuations of flow through the Bosphorus and Kerch]. Vodnie resursi (3), 184-186 (in Russian). 